\title{
Peningkatan Prestasi Belajar Matematika pada Materi Operasi Hitung Bilangan Bulat melalui Pendekatan Latihan Keterampilan Siswa SMP
}

\author{
Sugiyanto \\ SMP Negeri 1 Nusawungu, Cilacap \\ Rawabangus, Danasri, Nusawungu, Rawabangus, Danasri, Nusawungu, \\ Kabupaten Cilacap, Jawa Tengah \\ Email: bdmartono7@gmail.com
}

\begin{abstract}
Abstrak
Guru merupakan komponen yang berpengaruh terhadap terciptanya pendidikan didalam kelas, karena guru berinteraksi langsung dengan siswa dalam proses kegiatan belajar mengajar. Proses interaksi yang mendorong terjadinya belajar disebut juga pendidikan. Penelitian ini dilakukan di SMP Negeri 1 Nusawungu. Jenis penelitian yang dilakukan adalah Penelitian Tindakan Kelas yang dilaksanakan sebanyak dua siklus, masing-masing terdiri empat tahap yakni : perencanaan tindakan, pelaksanaan tindakan, observasi dan evaluasi, refleksi. Tujuan Penelitian Tindakan Kelas ini adalah untuk mengetahui pendekatan Latihan Keterampilan (Drill Method) dapat meningkatkan prestasi belajar matematika pada materi pokok Operasi Hitung Bilangan Bulat di kelas VII E SMP Negeri 1 Nusawungu Tahun Pelajaran 2015/2016. Kesimpulan Berdasarkan hasil penelitian mengenai pendekatan Latihan Keterampilan (Drill Method) pada mata pelajaran Matematika materi pokok Operasi Hitung Bilangan Bulat di kelas VII E SMP Negeri 1 Nusawungu Tahun Pelajaran 2015/2016 adalah bahwa pendekatan Latihan Keterampilan (Drill Method) dapat meningkatkan prestasi belajar siswa kelas VII E SMP Negeri 1 Nusawungu. Prestasi belajar siswa meningkat ditunjukkan dengan hasil ulangan harian pada masing-masing tahapan. Tingkat ketuntasan pada studi awal $31 \%$, siklus I $72 \%$, dan siklus II 91\%. Rata-rata hasil ulangan harian juga mengalami peningkatan yaitu 65 pada studi awal, 79 pada siklus I dan 87 pada siklus II. Sehingga terjadi rata-rata peningkatan total prestasi belajar dari kondisi awal ke siklus II 22.
\end{abstract}

Kata Kunci : Drill method, operasi hitung bilangan bulat, prestasi belajar

\begin{abstract}
The teacher is a component that affects the creation of education in the classroom, because the teacher interacts directly with students in the process of teaching and learning activities. The process of interaction that drives learning is also called education. This research was conducted at SMP Negeri 1 Nusawungu. This type of research is Classroom Action Research conducted in two cycles, each consisting of four stages: action planning, action implementation, observation and evaluation, reflection. The purpose of this Classroom Action Research is to find out the Skills Training approach (Drill Method) that can improve mathematics learning achievement on the subject matter of Round Number Calculations in Class VII E of SMP Negeri 1 Nusawungu in the 2015/2016 Academic Year. Conclusion Based on the results of research on the Skills Training approach (Drill Method) in Mathematics subject matter, the subject of Round Number Operations in Class VII E, SMP Negeri 1 Nusawungu, 2015/2016 Academic Year, is that the Skills Training approach (Drill Method) can improve student learning achievement in class VII E Public Middle School 1 Nusawungu. Improved student achievement is indicated by the results of daily tests at each stage. The completeness rate in the initial study was $31 \%$, cycle I was
\end{abstract}


$72 \%$, and cycle II was $91 \%$. The average results of daily tests also increased by 65 in the initial study, 79 in the first cycle and 87 in the second cycle. So that the average increase in total learning achievement from the initial conditions to the second cycle 22.

Keywords: Drill method, integer count operations, learning achievement

\section{PENDAHULUAN}

Pendidikan merupakan salah satu sarana untuk meningkatkan kualitas Sumber Daya Manusia. Pendidikan juga memegang peranan penting dalam usaha untuk mencapai manusia Indonesia seutuhnya. Undang - undang No. 20 pasal 3 tahun 2003 tentang Pendidikan Nasional menyatakan bahwa "Pendidikan Nasional berfungsi mengembangkan kemampuan dan membentuk watak serta peradaban bangsa yang bermartabat dalam rangka mencerdaskan kehidupan bangsa, bertujuan untuk berkembangnya peserta didik agar menjadi manusia yang beriman dan bertaqwa pada Tuhan Yang Maha Esa, berahlak mulia, sehat, berilmu, cakap, kreatifitas, mandiri dan menjadi warga negara yang demokratis serta bertanggung jawab”. Matematika merupakan bahan suatu kajian yang memiliki obyek abstrak dan dibangun melalui proses penalaran deduktif yaitu kebenaran suatu konsep diperoleh sebagai akibat logis dari kebenaran sebelumnya sudah diterima. Sehingga keterkaitan antar konsep dalam matematika bersifat sangat kuat dan jelas ( Kurikulum 2004). Hal tersebut di atas sesuai dengan tujuan dari pelajaran Matematika yaitu: (1) mempersiapkan siswa agar sanggup menghadapi perubahan keadaan di dalam kehidupan dan di dunia yang selalu berkembang melalui latihan bertindak atas dasar pemikiran secara logis, rasional kritis sistematis, cermat, jujur dan efektif; (2)Mempersiapkan siswa agar dapat menerapkan pola pikir Matematika dalam kehidupan sehari-hari (Muchtar A. Karim, 1996:10).

Hasil belajar dalam mata pelajaran Matematika perlu ditingkatkan, khususnya dalam operasi hitung bilangan bulat. Melalui implementasi pendekatan Latihan Ketrampilan (Drill Method) dalam proses belajar mengajar diharapkan dapat meningkatkan hasil belajar dengan peningkatan hasil nilai rata-rata minimal 75 khususnya pada materi pokok Operasi Hitung Bilangan Bulat dan meningkatnya prestasi belajar siswa. Prestasi belajar Matematika di SMP Negeri 1 Nuswungu masih relatif rendah, hal ini ditunjukan dari perolehan nilai rata-rata Ujian Nasional mata pelajaran Matematika pada tiga tahun terakhir, yaitu tahun $2012=7,32$ tahun $2013=8,53$ dan tahun $2014=$ 7,51. Menurut pengamatan peneliti bahwa kelas VII E dibandingkan dengan kelas lain nilai 
Matematikanya masih rendah. Salah satu penyebab rendahnya prestasi belajar adalah siswa kurang memahami konsep, aturan, struktur Matematika serta kurang aktif berpartisipasi dalam aktivitas pembelajaran di kelas. Hal ini ditunjukan dari perolehan nilai rata-rata ulangan harian yaitu 65. Dari situasi dan kondisi yang demikian itu maka penulis tertarik melakukan penelitian tentang "Peningkatan prestasi belajar matematika pada materi pokok Operasi Hitung Bilangan Bulat melalui pendekatan latihan keterampilan (Drill Method) di Kelas VII E SMP Negeri 1 Nusawungu Tahun Pelajaran 2015/2016”.

Sangat dimungkinkan adanya masalah dasar yang terkait di dalamnya atas dasar informasi yang diperoleh dari dokumen hasil ulangan harian. Dapat diidentifikasi masalah yang menjadi faktor penyebab rendahnya prestasi belajar Matematika di kelas VII E dalam semester I Tahun Pelajaran 2015/2016 adalah :

8. Motivasi belajar matematika masih rendah

9. Konsentrasi belajar siswa masih rendah

10. Siswa kurang memahami konsep yang dijelaskan oleh guru

11. Guru kurang menggunakan metode yang bervariasi

12. Guru kurang melibatkan siswa

Selanjutnya akan peneliti paparkan kajian teori dalam penelitian ini. Adapun kajian teori dalam penelitian ini sebagaimana dipaparkan dalam uraian berikut.

\section{Prestasi Belajar}

Menurut Saiful Bahri Djamarah (1994: 20-21) dalam bukunya Prestasi Belajar dan Kompetensi Guru, bahwa prestasi adalah apa yang telah dapat diciptakan, hasil pekerjaan, hasil yang menyenangkan hati yang, diperoleh dengan jalan keuletan kerja. Dalam buku yang sama, Nasrun harahap berpendapat bahwa prestasi adalah penilaian pendidikan tentang perkembangan dan kemajuan siswa berkenaan dengan penguasaan bahan pelajaran yang disajikan kepada siswa.

Menurut Abu Ahmadi dan Widodo Supriyono (1990: 130) "Prestasi belajar merupakan hasil interaksi antara berbagai faktor yang mempengaruhinya baik dari dalam diri (faktor internal) maupun dari luar (faktor eksternal) individu". Berdasarkan beberapa pendapat di atas bahwa prestasi belajar merupakan kegiatan yang dilakukan secara sadar dan rutin pada seseorang sehingga akan mengalami perubahan secara individu baik pengetahuan, keterampilan, sikap dan tingkah laku yang dihasilkan dari proses latihan dan pengalaman individu itu sendiri dalam berinteraksi dengan lingkungannya. 


\section{Pembelajaran Matematika}

Dalam Kamus Besar Bahasa Indonesia (Tim Penyusun KBBI, 2007:723) matematika diartikan sebagai: "ilmu tentang bilangan, hubungan antara bilangan, dan prosedur bilangan oprasional yang digunakan dalam penyelesaian masalah mengenai bilangan”. Dalam Peraturan Menteri Pendidikan Nasional No.22 (2006 : 417) mata pelajaran matematika bertujuan supaya peserta didik memiliki kemampuan sebagai berikut: (1) Memahami konsep matematika, menjelaskan keterkaitan antar konsep dan mengaplikasikan konsep atau alogaritma secara luwes, akurat, efisien, dan tepat, dalam pemecahan masalah; (2) Menggunakan penalaran pada pola dan sifat, melakukan manipulasi matematika dalam membuat generalisasi, menyusun bukti, atau menjelaskan gagasan dan pernyataan matematika; (3) Memecahkan masalah yang meliputi kemampuan memahami masalah, merancang model matematika, menyelesaikan model dan menafsirkan solusi yang diperoleh; (4) Mengomunikasikan gagasan dengan symbol, tabel, diagram, atau media lain untuk memperjelas keadaan atau masalah; (5) Memiliki sifat menghargai kegunaan matematika dalam kehidupan, yaitu memiliki rasa ingin tahu, perhatian, dan minat dalam mempelajari matematika, serta sikap ulet dan percaya diri dalam pemecahan masalah.

\section{Pendekatan Latihan Keterampilan (Drill Method)}

Latihan keterampilan (Drill Method) adalah suatu pendekatan mengajar, dimana siswa diajak ketempat latihan keterampilan untuk melihat bagaimana cara membuat sesuatu, bagaimana cara menggunakanya, untuk apa dibuat, apa manfaatnya dan sebagainya. Penggunaan pendekatan yang kurang tepat akan menimbulkan hal-hal yang negatif misalnya anak menjadi kurang kreatif dan kurang dinamis. Tetapi latihan yang praktis, mudah dilakukan, serta teratur melaksanakannya membina anak dalam meningkatkan penguasaan keterampilan itu, bahkan mungkin siswa dapat memiliki ketangkasan itu dengan sempurna. Di dalam Pendekatan latihan keterampilan (Drill Method) ini memiliki kelebihan dan kekurangan, yaitu:

1. Kelebihan metode latihan keterampilan (Drill Method)

a) Dapat memperoleh kecakapanan motoris, seperti menulis, melafalkan huruf, membuat dan menggunakan alat-alat.

b) Dapat memperoleh kecakapan mental, seperti dalam perkalian, penjumlahan, pengurangan, dan pembagian, tanda-tanda/simbol, dan sebagainya.

c) Dapat membentuk kebiasaan dan menambah ketepatan dan kecepatan pelaksanaan. 
2. Kekurangan dan keterbatasan metode latihan keterampilan (Drill Method) adalah sebegai berikut:
a) Menghambat bakat dan inisiatif anak didik karena anak didik lebih banyak dibawa kepada penyesuaian dan diarahkan kepada jauh dari pengertian.
b) Menimbulkan penyesuaian secara statis kepada lingkungan.
c) Kadang-kadang latihan yang dilaksanakan secara berulang-ulang merupakan hal yang monoton dan mudah membosankan.
d) Dapat menimbulkan verbalisme.

\section{METODE PENELITAN}

Penelitian tindakan kelas ini dilaksanakan dalam 2 siklus, yang tiap siklusnya dilaksanakan 2 kali pertemuan dengan alokasi waktu 2 x 40 menit tiap pertemuan. Setiap siklus terdiri dari kegiatan yang meliputi perencanaan, pelaksanaan tindakan, observasi, evaluasi, dan refleksi. Pada akhir siklus diadakan tes / evaluasi untuk mengetahui besarnya peningkatan hasil belajar matematika sesuai dengan penelitian. Pada siklus 1, dan 2 digunakan pendekatan kontekstual dan menggunakan prosedur penelitian dengan tahapan sebagai berikut :

Gambar 1. Prosedur Penelitian

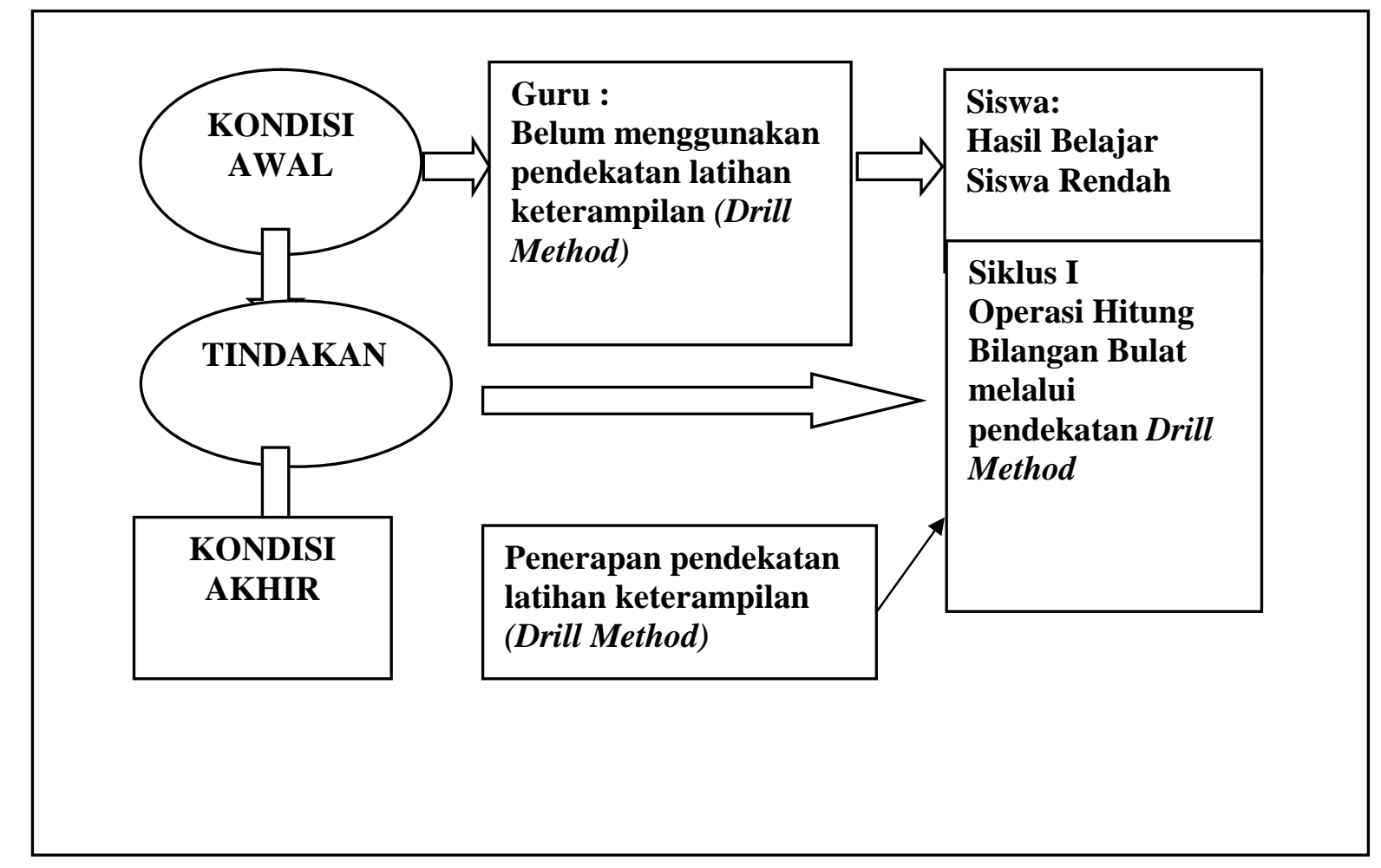

Subyek penelitian ini adalah siswa kelas VII E SMP Negeri 1 Nusawungu Kabupaten Cilacap dengan jumlah siswa 32 terdiri dari 12 siswa laki-laki dan 20 siswa 
perempuan. Alasan memilih kelas VII E sebagai subyek penelitian, karena kondisi siswa kelas VII E dibandingkan dengan kelas yang lain prestasi belajar matematikanya masih rendah.

\section{HASIL DAN PEMBAHASAN}

Pada kondisi awal sebelum pendekatan latihan keterampilan (Drill Method) dilakukan, hasil belajar siswa masih rendah. Prestasi belajar siswa kelas VII E SMP Negeri 1 Nusawungu khususnya pelajaran matematika pada materi pokok Operasi Hitung Bilangan Bulat dianggap masih rendah. Setelah dilakukan pembelajaran dengan pendekatan Drill Method, hasil belajar siswa menjadi meningkat. Bisa kita lihat pada tabel berikut :

Tabel 1. Nilai Evaluasi Prestasi Belajar Matematika

\begin{tabular}{|c|c|c|c|c|c|}
\hline \multirow{2}{*}{ NO } & \multirow{2}{*}{ NAMA SISWA } & \multicolumn{3}{|c|}{ SIKLUS } & \multirow{2}{*}{ Rt. } \\
\hline & & UH & 1 & 2 & \\
\hline 1 & $\begin{array}{l}\text { AFRIZAL NUR } \\
\text { ROHMAN }\end{array}$ & 61 & 76 & 80 & 72 \\
\hline 2 & AISYAH NURUL 'AINI & 62 & 78 & 88 & 76 \\
\hline 3 & ALINDA SUTANTI & 65 & 88 & 92 & 82 \\
\hline 4 & ARNI PURWANTI & 56 & 68 & 80 & 68 \\
\hline 5 & BONDAN SADEWO & 76 & 85 & 90 & 84 \\
\hline 6 & DIAH PURNAMASARI & 64 & 88 & 94 & 82 \\
\hline 7 & DIMAS HIDAYAT & 66 & 90 & 95 & 84 \\
\hline 8 & DWI JAEKY RAMADAN & 54 & 65 & 78 & 66 \\
\hline 9 & FADIL RAMADAN & 60 & 75 & 88 & 74 \\
\hline 10 & $\begin{array}{l}\text { FATIMAH NISYAPURI } \\
\text { A. }\end{array}$ & 76 & 85 & 94 & 85 \\
\hline 11 & FERI KURNIAWAN & 77 & 82 & 90 & 83 \\
\hline 12 & FITRI RAMZI F & 77 & 86 & 90 & 84 \\
\hline 13 & HENDRIANA RISTANTI & 64 & 85 & 90 & 80 \\
\hline 14 & HOERUL ANAM & 78 & 88 & 95 & 87 \\
\hline 15 & INDRA NOVI PERDANA & 78 & 90 & 96 & 88 \\
\hline 16 & ISTANTI & 76 & 84 & 92 & 84 \\
\hline 17 & JAKA TRISABTO & 58 & 72 & 80 & 70 \\
\hline 18 & KAYLA RISMA F & 52 & 65 & 70 & 62 \\
\hline 19 & LAURA PUSPITA SARI & 75 & 85 & 90 & 83 \\
\hline 20 & LUSIA KUMALA DEWI & 64 & 80 & 92 & 79 \\
\hline 21 & MEILDA ROSYANA S. & 52 & 60 & 70 & 61 \\
\hline 22 & NADIRA NUR ASITA & 60 & 76 & 85 & 74 \\
\hline 23 & NIKEN DIAN LESTARI & 52 & 60 & 72 & 61 \\
\hline 24 & $\begin{array}{l}\text { NOVA DWI } \\
\text { RAHMAWATI }\end{array}$ & 79 & 92 & 96 & 89 \\
\hline
\end{tabular}




\begin{tabular}{|c|c|c|c|c|c|}
\hline 25 & PUTRI DWI SEPTIANI & 84 & 90 & 95 & 90 \\
\hline 26 & $\begin{array}{l}\text { RICKY BUDI } \\
\text { HERMAWAN }\end{array}$ & 58 & 70 & 85 & 71 \\
\hline 27 & SHALSA BILLA F. T. & 60 & 72 & 86 & 73 \\
\hline 28 & TEGAR PRAVASTARA & 60 & 77 & 88 & 75 \\
\hline 29 & WIJI SAFITRI & 54 & 65 & 82 & 67 \\
\hline 30 & YEA ZABIT ZAUTHA & 62 & 80 & 88 & 77 \\
\hline 31 & YOGA SAPUTRA & 66 & 80 & 90 & 79 \\
\hline 32 & YOLLA PERMITA DEWI & 64 & 78 & 86 & 76 \\
\hline & Rata-rata & 68 & 79 & 87 & 87 \\
\hline & Tertinggi & 87 & 92 & 96 & 90 \\
\hline & Terendah & 52 & 60 & 70 & 61 \\
\hline
\end{tabular}

Prestasi belajar siswa pada kondisi awal atau pra siklus hanya ada 10 siswa yang tuntas atau sebesar 31\%. Sedangkan pada siklus I meningkat menjadi 23 siswa yang tuntas atau sebesar $72 \%$ atau 23 dan meningkat $41 \%$ dari studi awal. Nilai rata-rata pada kondisi awal 65 mengalami peningkatan pada siklus I dengan nilai rata-rata 79. Pada siklus II, peneliti melakukan revisi pada RPP dan skenario tindakan. Pada siklus II peneliti memberikan perhatian khusus pada siswa yang masih pasif berdasarkan pengamatan pada siklus sebelumnya. Ketuntasan belajar mengalami peningkatan 19\% dari siklus I, yang semula $72 \%$ menjadi $91 \%$ pada siklus II. Ada 29 siswa mendapatkan nilai diatas KKM pada siklus II dengan nilai rata-rata 87, sehingga dapat dikatakan bahwa ketuntasan belajar rata-rata pada kondisi awal, siklus I dan siklus II mengalami kenaikan yang sangat signifikan. Dengan demikian, maka kegiatan penelitian tindakan kelas dinyatakan telah berhasil.

\section{KESIMPULAN}

Berdasarkan hasil penelitian dengan menggunakan pendekatan latihan keterampilan (Drill Method) pada mata pelajaran Matematika di kelas VII E SMP Negeri 1 Nusawungu tahun Pelajaran 2015/2016 maka dapat ditarik kesimpulan bahwa Prestasi belajar siswa meningkat. Hal ini dibuktikan dengan hasil ulangan harian pada masing-masing tahapan. Tingkat ketuntasan pada studi awal sebesar $31 \%$ dan mengalami peningkatan pada siklus I sebesar 72\% serta pada siklus II lebih meningkat lagi menjadi 91\%. Rata-rata hasil ulangan harian juga mengalami peningkatan yaitu 65 pada studi awal, dan meningkat menjadi 79 pada siklus I serta mengalami peningkatan lagi sebesar 87 pada siklus II. Sehingga terjadi rata-rata peningkatan total prestasi belajar dari kondisi awal ke siklus II 22. 


\section{SARAN}

Perlu dilakukan penitian tindakan kelas dengan berbagai pendekatan pembelajaran yang lain

\section{DAFTAR PUSTAKA}

Abdusysyakir. (2007). Sejarah Matematika dan Perkembangannya. Yogyakarta : Tiara Wacana Yogya.http://rujukanskripsi.blogspot.com/2013/06/kajian-teori-hakikathasil-belajar.-html\#sthash.I3f03XXT.dpuf.

Abu Ahmadi dan Supriyono Widodo. (1990). Psikologi Pendidikan. Jakarta : PT. Rineka.

A.Karim, Muchtar. (1996). Pendidikan Matematika 1. Malang : Depdikbud.

Andayani, dkk. (2009). Pemantapan Kemampuan Profesional. Jakarta : Universitas Terbuka.

Alwi, dkk. (2007). Kamus Besar Bahasa Indonesia. Jakarta : Balai Pustaka.

Bruner. Jerome. (1966). Toward a Theory of Instruction. Cambridge : Havard.

Bukhori. (1997). Pengantar Psikologi pendidikan. Bandung : Jermore.

Daryanto. (1998). Administrasi Pendidikan. Jakarta : Rineka Cipta.

Depdiknas. (2006). Permendiknas No. 22 Tahun 2006 Tentang Standar Isi. Jakarta : Depdiknas.

Djamarah, Syaiful Bahri. (1994). Prestasi Belajar dan Kompetensi Guru. Surabaya : Usaha Nasional.

Fauzi, Akhmad. (2006). Upaya Meningkatkan Prestasi Belajar Siswa Kelas VII D MTs Nurul Ulum Jembayat Dalam Operasi Hitung Bilangan Bulat Melalui Pemanfaatan Alat Peraga Garis Bilangan. Skripsi. Unnes.

http://rujukanskripsi.blogspot.com/2013/06/kajian-teori-hakikat-hasil-belajar.html\#sthash.-I3f03XXT. diunduh tanggal 10 Agustus 2015.

http://www.jaringinfo.com/2012/kumpulan-macam-macam-metode-pembelajaran diunduh tang-gal 10 Agustus 2015.

Karso, dkk. (2010). Materi Pokok Pendidikan Matematika I. Jakarta : Unversitas Terbuka.

M. Cholik, dkk. (2000). Metodik Khusus Pengajaran Berhitung di SD. Jakarta : Depdikbud.

Munandar, Utami. (1987). Mengembangkan Bakat Serta Kreatifitas Anak Sekolah. Jakarta. Gramedia. 
Nasution, Andi Hakim. (1978). Landasan Matematika. Jakarta : Bharata Karya Aksara.

Puji Santosa, dkk. (2011). Robert. M. Cagne (1984). Materi dan Pembelajaran Bahasa Indonesia di SD. Jakarta : Universitas Terbuka.

Ruseffendi, E.T, dkk. (1992). Pendidikan Matematika 3. Jakarta : Depdikbud.

Sagala, S. (2009). Pengertian Pembelajaran. Diunduh 10 Agustus 2015 dari https://trys99.wordpress.com/2014/08/17/pengertian-pembelajaran-menurut-paraahli/

Slameto. (1995). Belajar dan Factor-faktor yang Mempengaruhinya. Jakarta : Renika Cipto. http://rujukanskripsi.blogspot.com/2013/06/kajian-teori-hakikathasil.belajar.html\#-sthash.-I3f03XXT.dpuf.

Trianto. (2010). Corey. (1986). Pengertian Pembelajaran. Diunduh 10 Agustus 2015 dari http://dedi26.blogspot.com/2013/04/pengertian-pembelajaran-menurut-para.html

Undang-undang Nomor 20 Tahun 2003 Tentang Sistem Pendidikan Nasional. 